\title{
A PERCEPÇÃO DO PROFISSIONAL DE SAÚDE DIANTE DO ÓBITO INFANTIL
}

\author{
HEALTH PROFESSIONAL PERCEPTION ABOUT INFANT DEATH
}

\author{
Guedes, JKKO ${ }^{1}$; Guedes, SAM ${ }^{2}$, Follador, FAC ${ }^{1}$; Vieira, $\mathrm{AP}^{1}$; Yamada, $\mathrm{RS}^{1}$; Pereira, $\mathrm{AC}^{1}$; \\ Ferreto, LED $^{1}$; \\ Afiliações: 1- Centro de Ciências da Saúde, curso de medicina, da Universidade Estadual do Oeste do Paraná. 2- Centro de Ciências \\ Médicas e Farmacêuticas, curso de medicina da Universidade Estadual do Oeste do Paraná. \\ Endereço do autor de correspondência Rodovia PR-182 Km 02 - Bairro Água Branca/Francisco Beltrão, Paraná, Brasil. CEP: 85601-970. \\ Lirane.ferreto@unioeste.br
}

\section{Resumo}

A presente investigação teve como objetivo analisar a perspectiva, reações e sentimentos dos profissionais de saúde a respeito dos óbitos infantis. Pesquisa qualitativa e descritiva desenvolvida na área de abrangência da $8^{\text {a }}$. Regional de Saúde de Francisco Beltrão junto aos profissionais de saúde na área de cobertura de mães que tiveram perda infantil. Cinco profissionais, que em algum momento tiveram contato com o infante que foi a óbito, foram entrevistados através de um questionário semi-estruturado norteado por pontos que abordavam a concepção em relação à morte. Identificouse na análise três categorias: 1) percepção da morte e do morrer; 2) da formação acadêmica à prática profissional e 3) evocações e crenças. Conclui-se que existe a necessidade de implantação de política que preparem os profissionais da saúde para lidar com a morte e o morrer a fim de que a arte de lidar com seres humanos seja menos penoso, triste e estressante.

Palavras-chave: morte; mortalidade infantil; profissionais de saúde.

\section{Abstract}

This research aimed to analyze the perspective, reactions and feelings of health professionals regarding infant deaths. qualitative and descriptive research developed at the 8th coverage area. Health Regional Francisco Beltrao with health professionals in mothers of coverage area that had infant loss. Five professionals who at some point had contact with the infant who died, were interviewed through a semi-structured questionnaire guided by points that addressed the design in relation to death. It was identified in the analysis three categories: 1) perception of death and dying; 2) academic education to professional practice and 3) evocations and beliefs. It is concluded that there is a need for policy implementation to prepare health professionals to deal with death and dying so that the art of dealing with human beings is less painful, sad and stressful.

Keywords: death; infant mortality, health professionals. 


\section{Introdução}

No mundo, o coeficiente de mortalidade

infantil tem sido utilizado como um dos principais indicadores da qualidade de vida da população, além de ser importante na identificação do nível de desenvolvimento e do acesso aos serviços de saúde (1-2).

Dados divulgados pela ONU apontam uma queda de $75 \%$ da mortalidade infantil no Brasil de 1990 a 2012, mas o Paraná ainda apresenta uma das maiores taxas da Região Sul (2). Dados da Sesa (2014) apontam que 12,12 crianças morreram para cada mil nascidas em 2010. Em Santa Catarina, o índice foi de 10,41 por mil e no Rio Grande do Sul chega a 11,18, de acordo com o Sistema de Informações sobre Mortalidade (SIM), do governo federal, em dados prévios(2).

Em 2003, o Paraná apresentava uma taxa de mortalidade infantil de 16,3 mortes por mil nascidos vivos e esta taxa, ao longo de 10 anos, decresceu gradualmente atingindo um índice inferior a 12 mortes por mil nascidos vivos. Nesse contexto, o município de Francisco Beltrão estava na contramão do estado ao apresentar em 2011, por exemplo, uma taxa de inconcebíveis 22,7 óbitos para cada mil nascidos vivos (2). Não obstante, uma avaliação meramente numérica dos óbitos, registrados nos Sistemas de Informação sobre Mortalidade (SIM) e de Nascidos Vivos (SINASC), não permite um entendimento mais profundo do fenômeno relacionado à mortalidade infantil (3).

Para ampliar essa visão é que se pretende buscar a perspectiva dos profissionais de saúde frente a essa realidade, mostrando uma outra face impossível de se quantificar em indicadores numéricos, ou seja, quais foram as explicações, juízos e percepções daqueles que estão em contato contínuo com a realidade da morte. Apesar de a morte ser um evento biológico e inevitável de qualquer ser vivente, ela permanece sendo encarada como um acontecimento alheio e distante da realidade. Dessa forma, esse fenômeno acaba ficando banalizado pela sociedade o que impede que se elaborem meios mais eficazes de se lidar, discutir e conhecer a mesma (4).

Isso decorre porque ainda hoje prevalece o paradigma cartesiano, também conhecido como método de Descartes, o qual fragmentou a realidade, bem como as disciplinas acadêmicas modernas, generalizou e reduziu a ciência ao ponto de levar os profissionais da saúde a compreenderem o corpo humano como uma 
máquina que pode ser analisada de forma fragmentada (5).

Esse método resultou em um ensino acadêmico que tem por finalidade, de forma geral, formar profissionais de saúde que atuem com ênfase na cura das doenças e no combate à morte e não de profissionais que lidem com seres humanos que eventualmente estão doentes e que inevitavelmente virão a óbito, uma vez que essa é uma condição intrínseca à vida (6). Prova disso é que já nos primeiros anos da formação acadêmica, na área da saúde, os estudantes passam a compreender a morte pela via da negação, pois nas aulas de anatomia há uma despersonalização do paciente, o qual passa a ser significado por um cadáver, um tecido ou, meramente, um órgão (7). Isso ajuda a explicar o fato de a morte ser tão camuflada e mascarada nos ambientes hospitalares pela equipe de saúde, por meio de frases prontas como "o paciente foi a óbito" e por meio de procedimentos burocráticos e técnicos a fim de rapidamente desfazerem-se do corpo agora sem vida (7).

A morte, em si, já é um processo muito penoso e quando ocorre em crianças, essa adquire uma face mais sombria já que interrompe de forma brusca o que se esperava ser o ciclo natural da vida. Auxiliar os profissionais a compreender a singularidade do fenômeno da morte, implica na necessidade de se ter uma educação humanizada com foco na integralidade e em uma visão biopsicossocial. Essa visão biomédica, que impera no mundo ocidental, apesar de parecer intransponível, poderia ser transcendida a partir de uma perspectiva integradora. Isto é, permitir a comunicação entre as especialidades que a medicina desenvolveu ao longo da história (6).

Com isso, essa discussão formará profissionais mais éticos, atentos e humanos, que entendam a morte, principalmente àquelas relacionados à faixa etária infantil, como um componente natural da vida e não como uma patologia que necessite de cura ou medicamento (4).

O objetivo desta pesquisa é de analisar a perspectiva, reações e sentimentos dos profissionais de saúde a respeito dos óbitos infantis.

\section{Métodos}

Este estudo se fundamentou em uma pesquisa qualitativa, descritiva, a qual trabalhou com a significação advinda da morte infantil pelo profissional de saúde. Além disso, também foram abordadas as inquietações geradas durante 
a realização dos procedimentos pós-morte, principalmente, quais foram os sentimentos gerados no profissional frente à morte de uma criança sob seus cuidados.

A pesquisa foi desenvolvida no território da Oitava Regional de Saúde junto aos profissionais de saúde na área de cobertura de mães que tiveram perda infantil. Para o estudo, o Comitê de Mortalidade Regional indicou o caso de uma criança nascida no município de Marmeleiro, que foi atendida nas Unidades Básicas de Saúde de Francisco Beltrão e Marmeleiro e no Hospital Regional do Sudoeste. A coleta de dados foi realizada em maio de 2016.

O Comitê auxiliou na indicação dos profissionais entrevistados durante a vigência do estudo. Os profissionais selecionados atuam no município de Francisco Beltrão, Paraná, Brasil e para participarem do estudo, assinaram o Termo de Consentimento Livre e Esclarecido.

A entrevista foi previamente agendada, conduzida em local reservado, e respeitada a vontade do profissional em relatar ou não a sua experiência frente à perda do paciente e diante de um questionário semi-estruturado. Segundo Minayo (8), a entrevista semi-estruturada envolve questões abertas e fechadas permitindo ao entrevistado o relato aberto sobre o tema proposto. As entrevistas foram gravadas em gravador digital, transcritas e devolvidas aos participantes para seu consentimento final. Foi mantido o sigilo dos nomes dos profissionais sendo substituídos por um número.

A entrevista norteou-se por pontos que abordam o entendimento e concepção em relação à morte, como o profissional se sente diante da perda de uma criança e o enfrentamento na realização da assistência a mãe e a família. Produziu-se uma análise temática, a partir da identificação dos núcleos de sentido que compõe uma comunicação, cuja frequência possua relação com o objeto analítico visado. A análise temática passou a ser conduzida em três etapas: a pré-análise, tratamento dos resultados obtidos e interpretação (8). O projeto foi aprovado pelo comitê de Ética e Pesquisa da Universidade Estadual do Oeste do Paraná (UNIOESTE), número do parecer 1.545.258.

\section{Resultados}

Os cinco profissionais de saúde incluídos na amostra estiverem, em algum momento, em contato com o infante que foi a óbito - desde o pré-natal até sua morte. A análise dos dados evidencia que os profissionais são predominantemente do sexo feminino, solteiros, 
sem filhos e com idade média de 30 anos (Tabela

1).

Todos os entrevistados relataram não ter

filhos e declararam seguir a religião católica.

Em relação ao caso, indicado pelo

Comitê de Mortalidade Regional, é sabido que a mãe iniciou o pré-natal em ESF do município de Marmeleiro-PR e foi transferida para Francisco Beltrão, onde procurou duas vezes o serviço de saúde. Buscou - na última consulta - unidade saúde devido ao parto prematuro; a criança nasceu no limite da viabilidade, com 23 semanas. Após nascimento, permaneceu por 19 dias na UTI neonatal do Hospital Regional do Sudoeste, tendo piora súbita de seu quadro, o que provocou sua morte.

Tabela 1. Perfil dos profissionais de saúde incluídos na amostra

\begin{tabular}{lcc}
\hline Variável & Quantidade & \\
\hline Sexo & & \\
Masculino & 2 & 40 \\
Feminino & 3 & 60 \\
\hline Idade & &
\end{tabular}

\begin{tabular}{lll} 
Menos de 25 anos & 1 & 20 \\
$25-30$ & 1 & 20 \\
30 ou mais & 3 & 60 \\
\hline
\end{tabular}

Formação

Médico

Enfermeiro
20

60
Técnico de enfermagem

1

20

\section{Serviço que atua}

UTI neonatal 3 60

ESF Marmeleiro 1 20

\begin{tabular}{lll} 
ESF Francisco Beltrão & 1 & 20 \\
\hline Fonte: Elaboração própria a partir de dados coletados na &
\end{tabular} pesquisa, 2016.

\section{Discussão}

Categoria 1: Percepção da morte e do morrer

Para que haja uma compreensão mais clara a respeito dos termos morte e morrer, necessária se faz a diferenciação entre eles. “ $A$ morte é o final da vida material, tal como nós conhecemos. E o morrer é o ato pelo qual ocorre a morte" (9).

A morte faz parte do ciclo evolutivo da vida uma vez que o indivíduo nasce, cresce, se desenvolve e morre, ou seja, ela faz parte da realidade humana. Segundo Diego Amaral da Costa em seu livro Humanidade (10): "Nós todos vamos morrer. E, acredite ou não, esse é um evento tão natural quanto nascer, crescer ou ter filhos. No entanto, a ideia da finitude nos enche de terror.".

Ocorre, no entanto, que a aceitação de alguns ciclos - e, no caso em comento - o da morte, varia de acordo com os contextos biológicos, culturais, sociais e de religiosidade. Para alguns "a morte é encarada como um 
fenômeno comum, rotineiro", mas para muitos o "morrer é triste demais sob vários aspectos, sobretudo é muito solitário e desumano" (11).

Sobre a morte e os sentimentos que ela desperta, De marco et al (12) coloca que:

A morte desperta, acima de tudo, medo: medo de perder a própria vida ou de perder um ente querido. Do ponto de vista psicanalítico, Eizirik (14) nos lembra que a morte desperta fantasias e correspondentes defesas contra elas. A morte representa o incontrolável, o inatingível, o desconhecido e o inominável. Por isso, sentimos medo, o qual, na maior parte do tempo, negamos, ou seja, não pensamos em tudo o que pode nos acontecer o tempo todo, pois, se assim fosse, não sairíamos de casa, e ficar em casa também seria perigoso.

O célebre escritor, Rubem Alves, referindo-se à morte e o morrer declarou "Já tive medo da morte. Hoje não tenho mais. $O$ que sinto é uma enorme tristeza" (13).

Quando a morte encerra a vida de uma criança, que é o estágio inicial dessa trajetória, as dúvidas, os questionamentos e a perplexidade são ainda maiores, pois fica a impressão de que ela chegou cedo demais, especialmente para a profissional mulher que logo pensa na perda de um filho. Essa passagem, dolorosa e inaceitável para a família, causa inquietação e desconforto também para os profissionais de saúde que acompanham o fim de uma trajetória recéminiciada (15). Alguns trechos das entrevistas realizadas corroboram tal fato:

"A gente sempre vai sentir que perdeu alguma coisa. Tem vezes que a gente chora junto com a família, principalmente com os que ficam mais tempo, que a gente cria um vínculo maior ainda (...) todo mundo fica mais triste, como se a tristeza ficasse até terminar seu plantão. Aí no outro dia você já está recuperado, você teve seu tempo em casa pra refletir também. (...) De imediato a gente não se sente nada bem, porque a gente é uma parcela muito pequena da equipe (EA)”.

Dessa forma, é forçoso afirmar que o óbito de um infante é muito traumático para toda a equipe de profissionais que acompanha o desenrolar do tratamento e o fim de uma vida, prematuramente.

O óbito de uma criança evidencia uma inversão do ciclo biológico e a interrupção das projeções paternas para o futuro do filho. Diante disso, essa morte precoce é mais dolorosa e, frequentemente, concebida como uma 
monstruosidade, provocando sentimentos de injustiça e crueldade tanto para a família, quanto para os profissionais de saúde (16).

Muitos dos que trabalham na área da saúde, se apegam ao doente e à sua família, tornando-se, dessa forma, mais triste e angustiante o enfrentamento do processo de morrer de seus pacientes. Essa afinidade que se estabelece, torna mais crucial o momento da comunicação do óbito para a mãe da criança (17). Isso pode ser verificado no discurso de EA, quando verbaliza:

"Desde o primeiro momento que a gestante inicia o acompanhamento, nós já criamos um vínculo com ela, como se tivéssemos uma responsabilidade sobre essa gestante. Então quando o desfecho é desfavorável, nós nos sentimos mal, como se pudéssemos ter feito alguma coisa para evitar esse óbito. "

MR conclui que quando a morte ocorre por "motivo evitável ou por um motivo não evitável, mas de forma rápida ou em alguns casos que você cria uma empatia diferente pela família, porque sabe da história ou conhece alguma coisa - como uma mãe que perdeu vários filhos -, isso, com certeza, nos deixa mais abalados".
Ainda, o sentimento vivenciado pelos profissionais, muitas vezes é de impotência e de culpa, como podemos identificar na fala de EC que declara que "fica um sentimento de culpa, abalo, mesmo sabendo que nem sempre podemos evitar isso".

Nesse contexto, a morte, quer queira, quer não, é uma realidade inexorável e é a única certeza que persegue a vida, embora, sem data marcada para acontecer, fato asseverado no discurso de MR: "a morte faz parte da existência humana quer seja para um adulto em seus 80 ou 90 anos, quer seja para um bebê no limite da viabilidade".

Diante do exposto e das considerações feitas pelos profissionais da saúde, a morte é uma certeza, ou seja, é a última etapa da vida. Mas o morrer é algo, ainda, inconcebível, inaceitável e triste, inda mais quando se refere à morte de um infante. $\mathrm{O}$ sentimento experimentado por quem acompanha o evento morte não se traduz em palavras, é indescritível.

Categoria 2: Da formação acadêmica à prática profissional

O Brasil tem avançado na busca efetiva da qualidade na formação acadêmica dos estudantes e, no caso específico, dos futuros profissionais da saúde. No entanto, um resultado 
satisfatório frente a ações concretas ainda está longe de ocorrer, inviabilizando uma preparação adequada face aos desafios que a atividade impõe.

No decorrer de sua trajetória acadêmica, o profissional da saúde recebe orientações de como lidar com situações adversas, e, mais especificamente com o evento da morte, porém, de forma muito tímida e genérica. Não há uma disciplina específica, não há um treinamento e nem a disposição para tratar a respeito do assunto. Apesar dessa deficiência na formação acadêmica, a maioria dos alunos se considera preparada para lidar com a morte. $(18,19,20)$. EC ratifica o exposto em seu discurso: "Na formação não há esse contato, apenas com a experiência do dia a dia é que aprendemos a lidar com essas situações".

Devido a essas falhas, os estudantes de cursos da saúde podem se formar sem terem tido contato com conceitos e ideologias sobre a morte e o morrer, fazendo com que eles possam agir de maneira inesperada pelo pesar e não conseguir cuidar do indivíduo que está vivenciando a finitude (19).

Apesar de não ter na grade curricular acadêmica uma disciplina específica que cuide do assunto e nem haver suporte técnico e psíquico no que diz respeito ao enfrentamento da morte e do morrer, alguns professores e orientadores de formação acadêmica, se preocupam com essa questão, fazendo o diferencial na preparação de seus discentes. Diante disso, MR afirma que: "Na minha residência de pediatria (não na de UTI), nós tivemos um preceptor, chamado de Dr. Izrail Cat, que era uma pessoa que se interessava muito por essa questão de morte e morrer dignamente. Então, eu tive um bom aprendizado com ele".

$\mathrm{Na}$ verdade, muitas instituições de saúde que empregam os profissionais também não apresentam nenhuma política de orientação e direção para o desenvolvimento de habilidades técnicas e procedimentos humanos éticos diante da fragilidade que acomete o doente. ET corrobora o exposto, ao expressar: "Não recebi informação, a instituição aqui não ofereceu, nem a instituição de onde vim”, o que contradiz o preceito de que é preciso cuidar da emoção dos que cuidam daquele que está morrendo (21).

Nesse contexto, é fundamental explicitar que, segundo Cruz, Garofalo, Sabino, \& Nascimento (22):

"É preciso preparar os profissionais nos centros de formação para lidarem com a morte, não apenas tecnicamente, 
mas emocionalmente, embora saibamos que sempre será difícil viver este momento, pois sob qualquer ponto de vista; profissional, pessoal, cultural, estaremos lidando com a sensação de perda de um ser humano".

Os profissionais, cientes dessa carência e obrigados a conviver com a morte no desempenho de suas funções, acabam por se empenhar num aprendizado solitário e prático (23). MR mostra-se muito preocupado com essas questões e diz: "Esse é um assunto que eu particularmente me interesso e leio bastante. Então, aprendendo e estudando, estou crescendo nessa área".

O insigne Rubem Alves assim se posicionou a respeito de uma nova especialidade médica para orientar os profissionais que cuidam das pessoas que estão num leito de morte: "Cheguei a sugerir uma nova especialidade médica, simétrica à obstetrícia: a "morienterapia", o cuidado com os que estão morrendo" (24).

Os trabalhadores da área da saúde, então, utilizam de diferentes maneiras para lidar com a morte. Enquanto alguns projetam maior cuidado e empatia, outros se apoderam de máscaras frias e impassíveis, aparentando uma dominação completa de todo o processo. Ocorre que, estes - ao barrar as verdadeiras sensações e exaltar as simulações - passam a desenvolver uma “indigestão" psicológica $(18,25)$.

Nesse sentido, Alves Brasil et al (26) afirma que:

Assistir a pessoas sofrendo, especialmente quando nada ou muito pouco se pode fazer, torna-se, frequentemente, algo penoso, porque lembra o profissional da saúde de que, como seres humanos idênticos aos pacientes, ele também é suscetível a essas situações e que não pode modificar o curso da vida que se encaminha para a morte. Então, para que não se torne insuportável lidar com doenças e morte, lança-se mão de mecanismos de defesa que podem ser bastante úteis, como humor e negação, mas que, por outro lado, podem tornar o profissional resistente a sentir empatia pelos pacientes.

Sob o mesmo prisma, os profissionais expressam caracteres de personalidade, valores de personalidade, valores de representação e do mundo e do ser humano. Nesse contexto, podem ser descritas quatro posturas profissionais e as 
enumera: 1) Calosidade profissional, 2) distanciamento crítico, 3) empatia genuína e 4) profissionalismo afetivo (27).

No presente estudo é possível identificar, claramente, essas posturas nos profissionais entrevistados. EA garante: "Você nunca vai estar preparado para ter uma morte no local de trabalho, mesmo que ela ocorra todo dia. Sempre vai ter aquela angústia e tristeza da perda, porque a gente não quer perder ninguém”. Nesse caso, foi empregada a empatia genuína, que se reduz à prática adotada pelo profissional de saúde que se envolve com o doente de um modo singelo, sem o estabelecimento de qualquer barreira (27).

Verifica-se, no depoimento de EA que alguns profissionais da saúde sentem tristeza e angústia quando há a perda de uma vida, observando-se que no ambiente de trabalho " $a$ conversa já é bem menor, falamos apenas o necessário, sem brincadeiras. $O$ ambiente apresenta esse momento da perda do nenê". O mesmo sentimento envolve ET quando afirma: "ficamos bem sentidos e procuramos saber o que aconteceu (...) embora a gente tenha um ritmo profissional, também temos o lado humano".
Já a calosidade profissional, definida como a indiferença com o sofrimento de pacientes, adquirida por profissionais da saúde depois de anos de trabalho, demonstrando a insensibilidade dos mesmos frente ao sujeito adoecido (27), também é relatada por EL: “quanto mais tempo você está na profissão, mais tempo e experiência você tem, na assistência, enfermagem, atendimento direto ao paciente, melhor você consegue lidar ou mascarar, talvez, o seu sentimento, o que você está sentindo".

A reação de outros, quando há a perda de um paciente, revela que a característica da calosidade profissional é mais frequente do que se imagina, conforme averbada por MR: "como as pessoas daqui já são bastante experientes nessa questão, se foi avaliado que foi feito tudo o possível e a criança realmente tinha uma doença grave que a levou a morte, não sendo favorável o prognóstico, mas ocorreu como algo que você já previa dentro da gravidade do quadro, existe, claro, a tristeza, mas já é um processo que está bem acomodado com a equipe da UTI”.

$\mathrm{Na}$ situação acima, MR adota o profissionalismo afetivo que ocorre quando o profissional de saúde mantém certo distanciamento do paciente, mas respeita a sua 
dor, isto é, o profissional se importa com a dor do paciente de forma controlada (27).

Já o distanciamento crítico tem a ver com a precisão do profissional de afastar os problemas trazidos pelo paciente, sem envolvimento pessoal e afetivo, se importando com a dor do paciente de forma controlada. Essa postura é mais difícil de ser adotada, uma vez que a dor e o sofrimento acabam sensibilizando os envolvidos (28).

É necessário que os profissionais de Saúde reflitam sobre a morte e o morrer em seu sentido emocional e social. O fracasso em fazêlo só pode trazer consequências funestas à relação entre eles e seus pacientes graves (20).

Outro fator que influencia as pessoas que trabalham em instituições de saúde é a forma como elas lidam com o estresse profissional causado, especialmente, pela finitude de seus pacientes. E, quando essa finitude se refere a uma criança, repise-se, a frustação é ainda maior. Alguns se revestem de uma couraça impermeável que se expressa por uma aparente frieza no trato com os pacientes e com as pessoas do seu convívio familiar. Outros se isolam do mundo não médico, deixando se envolver por um isolamento social que os impede de desfrutar de vários aspectos da vida. Já a negação e a minimização dos problemas relativos à profissão levam o profissional a desenvolver atitudes arrogantes e aparentemente insensíveis. Ainda se acrescenta nesse enfoque a ironia e o humor negro que esse profissional desenvolve através de uma linguagem irônica e amarga revelando a sua incapacidade de lidar com as frustrações e tristezas da tarefa profissional (28).

Diante desse cenário é imprescindível que os profissionais da saúde tenham um acompanhamento psicológico a fim de que possam atuar de forma equilibrada e prudente no exercício das suas atividades.

Algumas instituições de saúde oferecem aos seus colaboradores um acompanhamento psicológico através de profissionais capacitados, como afirma EA: "a gente sempre tem o apoio deles, que estão sempre nos acompanhando, principalmente quando ocorre a morte de alguém, então, eles estão sempre junto com a gente", entretanto ainda existe, em outros serviços, uma grande carência nesse setor.

Enfim, como já manifestado, o sentido da morte é um mistério que transpõe o princípio da vida, sendo considerado um grande enigma (16). E, mesmo com o grande avanço da engenharia, da ciência e da tecnologia a medicina ainda não consegue penetrar e nem 
desvendar esse grande enigma que é a morte. Mas, deve haver certamente, o respeito, o acompanhamento, e a assistência aos profissionais que atuam na área de saúde e que convivem - todos os dias - com a luta pela cura das doenças e pelo salvamento dos pacientes e que, muitas vezes, culmina com o termo da vida.

\section{Categoria 3: evocações e crenças}

A sociedade contemporânea procura ignorar ou evita falar sobre a morte, considerando-a como um tabu, algo pesado e lúgubre. $\mathrm{Na}$ verdade, não existe, em nossa cultura, uma linguagem clara e axiomática acerca do nosso deixar de existir. Há, a bem da verdade, uma rejeição no que se refere ao assunto (11).

As formas de lidar com a morte passaram por diversas construções ao longo dos séculos começando pela aceitação total, sendo considerada como uma provação, evoluindo pelo romantismo, percorrendo as vias da rejeição e culminando com a postura adotada contemporaneamente que é a negação, o silêncio, o tabu (16).

Várias são as crenças e comportamentos da sociedade - diante da morte e do morrer pelo mundo afora, mas a atitude da nossa civilização e cultura é bastante peculiar.

O mundo ocidental transformou a morte em tabu:

$$
\begin{aligned}
& \text { “ela costuma ser ocultada das crianças } \\
& \text { e banida das conversas cotidianas. Tudo } \\
& \text { aquilo que possa lembrá-la - a } \\
& \text { enfermidade, a velhice, a decrepitude- } \\
& \text { é escamoteado. Os doentes morrem no } \\
& \text { hospital, longe dos olhos - e, não raro, } \\
& \text { do coração-de seus amigos e parentes } \\
& \text { (10)”. }
\end{aligned}
$$

Para os profissionais que atuam na área de saúde, o sentimento causado pela morte de um paciente, especificamente no caso de crianças, é de insatisfação, negação, inconformismo e tristeza. EA relata:

"Você sempre vai ter uma alteração psicológica, nunca vai estar bem (...) tem momentos que você se segura para não chorar e outros momentos que você acaba chorando. (...) Sempre tem essa tristeza de ter perdido alguém (...) todo mundo fica apreensivo e angustiado. (...) Todo mundo fica mais quieto e o ambiente fica mais triste".

Ainda há aquela sensação de que algo poderia e deveria ser feito para evitar o desfecho 
indesejado, como descreve EC: "Quando o desfecho é desfavorável, nós nos sentimos mal, como se pudéssemos ter feito alguma coisa para evitar esse óbito".

É de fundamental importância o respeito à história, às culturas e às crenças dos pacientes e familiares pelos profissionais da saúde, inclusive se houver iminência de morte (22). Ademais, segundo Germano (29): "Essa difícil tarefa que extrapola a relação direta enfermeiro/paciente, estendendo-se também à família, exige nos dias atuais uma reformulação dos sentimentos de cada profissional sobre a morte e o morrer e mesmo a respeito da vida". Podemos acrescentar que essa prática de respeito e assistência deve ser observada por todos os profissionais que atuam na saúde.

Além disso, os profissionais de saúde deveriam ter o mesmo tempo de pesar a morte que as outras pessoas. Isso porque experimentar da sensação de tristeza, provocada pela morte, repetidas vezes pode gerar cansaço e irritabilidade, o que pode prejudicar a eficiência no trabalho e até interferir na sua vida pessoal e familiar (30).

$\mathrm{O}$ que deve ser observado pelos profissionais da saúde no exercício do seu mister é que o óbito de cada paciente é um evento único e não deve alterá-lo toda vez que isto ocorrer (31). Há a necessidade, então, que as instituições de saúde orientem e trabalhem para que os profissionais possam encarar o morrer como algo intrínseco à vida.

Ao mesmo tempo, estudos revelam que, a presença da religião tem se mostrado importante no cotidiano na vida das pessoas, através dela emergem práticas e representações dos cuidados com o corpo, que merecem ser compreendidas na atenção e saúde, pois oferecem suporte emocional, espiritual e social (32).

Em suma, essa exiguidade na preparação dos profissionais da saúde para lidar com a morte e o morrer precisa ser suplementada a fim de que a arte de lidar com seres humanos doentes e, especificamente daqueles que estão no epílogo da vida, seja menos penoso, menos triste e estressante.

\section{Conclusão}

Diante das explicações, juízos e percepções dos profissionais envolvidos nesse estudo, a morte e o morrer, especialmente quando se trata de crianças, é um evento muito traumático que causa tristeza, inquietação e desconforto para toda a equipe que acompanha o 
desenrolar do tratamento e o fim de uma vida, prematuramente.

No entanto, alguns tentam camuflar seus sentimentos fazendo uso de subterfúgios, tais como a frieza, o isolamento, arrogância, ironia, dentre outros. Não bastasse, o óbito de uma criança evidencia uma inversão do ciclo biológico e sua precocidade está envolvida com sentimentos de injustiça e crueldade tanto para a família, quanto para os profissionais de saúde que estabelecem vínculos, o que torna o enfrentamento do processo mais triste $\mathrm{e}$ angustiante.

Enfrentando a morte e lutando pela vida, os trabalhadores da área da saúde experienciam o constante desafio de salvar, curar ou aliviar. No entanto, constatou-se que existe a preparação e o cuidado para tratar, curar e salvar, esquecendo-se de que há a necessidade de um aprendizado para lidar com a morte e o morrer. Apenas a compreensão do processo da morte irá permitir que as equipes de saúde concebam a morte como parte integrante e fundamental da existência, e não como um desafio à vida $(18$, $33)$.

Tomando como base os resultados deste estudo, verificou-se a importância que os profissionais de saúde têm no acompanhamento dos infantes e, ainda, dos familiares destes, no caso de óbito. Por isso, a necessidade de terem um preparo psicológico e até espiritual a fim de que possam lidar, de forma equilibrada, com os sentimentos que envolvem esse processo.

Por fim, conclui-se que há uma necessidade premente de serem discutidos assuntos sobre a morte e o morrer no processo de formação dos profissionais de saúde, incluindo o tema em sua grade curricular, além de palestras, seminários e afins, uma vez que esse processo é uma realidade que faz parte do cotidiano de todos eles.

\section{Referências}

1. Basso CG, Neves ET, Silveira A. Associação entre realização de pré-natal e morbidade neonatal. Texto contexto - enferm. 2012; 21(2): 269-276. Disponível em http://www.scielo.br/scielo.php?script=sci_artte xt\&pid=S010407072012000200003\&lng=pt\&n $\mathrm{rm}=$ iso.

2. SESA. A vigilância epidemiológica dos óbitos maternos e infantis e a atuação dos comitês de prevenção da mortalidade materna e infantil. Disponível em: http://www.saude.pr.gov.br/arquivos/File/SPP Arquivos/comite_mort_mat_infant/2boletim_ep idemiologia.pdf.

3. Goulart LMHF, Somarriba MG, Xavier CC. A perspectiva das mães sobre o óbito infantil: uma investigação além dos números. Cad. Saúde Pública. 2005; 21(3): 715-723. Disponível em: http://www.scielo.br/scielo.php?script=sci_artte $\mathrm{xt} \& \mathrm{pid}=\mathrm{S} 0102-$ $311 \mathrm{X} 2005000300005 \& \operatorname{lng}=\mathrm{en} \& \mathrm{nrm}=\mathrm{iso}$. 
4. Silva ALL, Ruiz EM. Cuidar, morte e morrer: significações para profissionais de Enfermagem. Estud. psicol. (Campinas). 2003; 20(1): 15-25. Disponível

em: http://www.scielo.br/scielo.php?script=sci_artte $\mathrm{xt} \& \mathrm{pid}=\mathrm{S} 0103$ -

166X2003000100002\&lng=en\&nrm=iso.

5. Capra F. O ponto de mutação. São Paulo: Cutrix; 1982.

6. Combinato DS, Queiroz, MS. Morte: uma visão psicossocial. Estud. psicol. 2006. 11(2), 209-216. Disponível em http://www.scielo.br/scielo.php?script=sci_artte xt\&pid=S1413294X2006000200010\&lng=en\& nrm=iso.

7. Santos MA, Hormanez M. Atitude frente à morte em profissionais e estudantes de enfermagem: revisão da produção científica da última década. Ciênc. saúde coletiva. 2013; 18(9): 2757-2768. Disponível em: http://www.scielo.br/scielo.php?script=sci_artte xt\&pid=S1413-

$81232013000900031 \& \operatorname{lng}=$ en\&nrm=iso.

8. Minayo MCS. O desafio do conhecimento: pesquisa qualitativa em saúde. São Paulo: Hucitec; 2007.

9. D'Assumpção EA. Comportar-se fazendo bioética: para quem se interessa pela ética. Rio de Janeiro: Vozes; 1998.

10. Costa DA. Humanidade. Mitos, desejos, sonhos e esperanças. Joinville: Clube de autores; 2009.

11. Kubler-Ross E. Sobre a morte e o morrer: São Paulo: Martins Fontes; 1998.

12. De Marco MA. Psicologia médica: abordagem integral do processo saúde-doença. Porto Alegre: Artmed; 2012.

13. Alves R. Na morada das palavras. Campinas, SP: Papirus; 2003a.

14. Eizirik, C. O ciclo da vida humana: uma perspectiva psicodinâmica. Porto Alegre: Artmed; 2001.

15. Rezende AM, Santos GF, Caldeira, VP, Magalhães, ZR. Ritos de morte na lembrança de velhos. Revista Brasileira de Enfermagem. 1995; 48(1): 07-16.

16. Pampolha SSA. "Criança não deveria morrer": significados atribuídos por profissionais de saúde ao paliar crianças em iminência de morte [Dissertação de Mestrado]. Belém, PA: Universidade Federal do Pará.; 2013.

17. Mello TB. Comunicação de más notícias: experiência de mães de crianças e adolescentes com câncer [Dissertação de Mestrado]. Ribeirão Preto, SP: Escola de Enfermagem de Ribeirão Preto da Universidade de São Paulo; 2013.

18. Haddad DRS. A morte e o processo de morrer de crianças em terapia intensiva pediátrica: vivência do enfermeiro [Dissertação de Mestrado]. Belo Horizonte, MG: Curso de Mestrado da Faculdade de Enfermagem da Universidade Federal de Minas Gerais; 2006.

19. Oliveira PP, Amaral JG, Viegas SMF, Rodrigues AB. Percepção dos profissionais que atuam numa instituição de longa permanência para idosos sobre a morte e o morrer. Ciênc. saúde coletiva. 2013;18(9): 2635-2644. Disponível em http://www.scielo.br/scielo.pp?script=sci_arttex $\mathrm{t} \& \mathrm{pid}=\mathrm{S} 1413$

$81232013000900018 \& \operatorname{lng}=$ en\&nrm=iso

20. Lima VR, Buys R. Educação para a morte na formação de profissionais de Saúde. Arquivos Brasileiros de Psicologia. 2008. 60(3), 52-63.

21. Ferreira AMY, Wanderley KS. Sobre a morte e o morrer: um espaço de reflexão. Revista Temática Kairós Gerontologia. 2012. 15(12), 295-307. Disponível em http://www.revistas.pucsp.br/index.php/kairos/a rticle/ download/20038/14905.

22. Cruz C, Garofalo RC, Sabino T, Nascimento MAL. O "pacote" e a enfermagem: análise crítica de uma cena de morte. Rev.Bras. Enferm. 2000. 53(3), 467-471.

23. Penna CMM, Nova LSV, Barbosa S. A morte e seus Significados: um estudo compreensivo com professores e alunos de enfermagem. Revista de Enfermagem. 1999. 5(9), 20-38. 
24. Alves R. Sobre a morte e o morrer. São Paulo: Caderno Sinapse. Folha de S. Paulo; 2003b.

25. Santos GC, Cruz TT, Araujo FF, Gonçalves FM, Almeida ACV. Reflexões acerca do sentimento da equipe de enfermagem diante do processo morrer e morte da criança hospitalizada. Revista Rede de Cuidados em Saúde. 2010. 4(1), 1-13.

26. Brasil MAA. Psicologia médica - a dimensão psicossocial da prática médica. Rio de Janeiro: Guanabara Koogan; 2012.

29. Germano, RM. A ética e o ensino de ética na Enfermagem do Brasil. São Paulo: Cortez, 1993. $141 \mathrm{p}$.

30. Pincus L. A família e a morte: como enfrentar o luto. Rio de Janeiro: Paz e Terra; 1989.

27. Angerami-Camon, V. A Psicologia no Hospital. São Paulo: Traço; 1998.

28. Martins MCFN. Relação profissionalpaciente: subsídios para profissionais de saúde. Psychiatry On-line Brazil. 1997. 2(3). Disponível em: https://fanut.ufg.br/up/128/o/RELACAO_PRO FISSIONAL_PACIENTE.pdf
31. Silva LCSP. Sentimentos de profissionais de enfermagem diante da morte de recém-nascidos em uma unidade de terapia intensiva [Dissertação de Mestrado]. Natal, RN: Programa de Pós-Graduação em Enfermagem. Universidade Federal do Rio Grande do Norte; 2007.

32. Santos SS, Jesus LC, Portella SDC. A enfermagem e a abordagem da morte infantil: um estudo de trabalhos. Qualis A. Revista Enfermagem Contemporânea. 2013; 2(1): 112131.

33. Ferreira GC. Morte: o vivido da equipe de enfermagem cirúrgica [Dissertação de Mestrado]. Juiz de Fora, MG: Programa de PósGraduação em Enfermagem, Universidade Federal de Juiz de Fora; 2012.

Agradecimentos - agradecimentos a colaboradores entre outros poderão ser citados nesta seção, antes das referências.

Financiamento - citar as fontes de recursos de financiamento em ordem alfabética

Anexos - espaço para documentos importantes para o estudo, ex. instrumentos de coleta, tabelas de dados, análises estatísticas complementares, etc 